AperTO - Archivio Istituzionale Open Access dell'Università di Torino

\title{
Gestures as semiotic resources in the mathematics classroom
}

\section{This is the author's manuscript}

Original Citation:

Availability:

This version is available http://hdl.handle.net/2318/102246

since

Published version:

DOI:10.1007/s10649-008-9163-z

Terms of use:

Open Access

Anyone can freely access the full text of works made available as "Open Access". Works made available under a Creative Commons license can be used according to the terms and conditions of said license. Use of all other works requires consent of the right holder (author or publisher) if not exempted from copyright protection by the applicable law. 


\section{(3) \\ UNIVERSITÀ DEGLI STUDI DI TORINO}

The final publication is available at Springer via http://dx.doi.org/10.1007/s10649-008-9163-z 


\title{
Gestures as semiotic resources in the mathematics classroom
}

\author{
Ferdinando Arzarello Domingo Paola Ornella Robutti Cristina Sabena
}

\begin{abstract}
In this paper, we consider gestures as part of the resources activated in the mathematics classroom: speech, inscriptions, artifacts, etc. As such, gestures are seen as one of the semiotic tools used by students and teacher in mathematics teaching-learning. To analyze them, we introduce a suitable model, the semiotic bundle. It allows focusing on the relationships of gestures with the other semiotic resources within a multimodal approach. It also enables framing the mediating action of the teacher in the classroom: in this respect, we introduce the notion of semiotic game where gestures are one of the major ingredients.
\end{abstract}

Keywords Gesture $\cdot$ Multimodality $\cdot$ Semiotics $\cdot$ Semiotic bundle $\cdot$ Semiotic game

\section{Introduction}

The phenomenology of learning processes in the mathematics class shows a variety of actions and productions activated by the students and by the teacher using different resources: words (orally or in written form); extra-linguistic modes of expression (gestures, glances,...); different types of inscriptions (drawings, sketches, graphs,...); various 
instruments (from the pencil to the most sophisticated information and communication technology devices); and so on. Such resources are used with great flexibility: generally, the same person exploits many of them simultaneously. Sometimes, they are shared by the students (and possibly by the teacher) and used as communication or thinking tools. All such resources, with the actions and productions they support, are important for grasping mathematical ideas: In fact, they help to bridge the gap between the worldly experience and the more formal mathematics.

Grounding our work on these observations, we shall analyze how gestures enter into mathematics teaching-learning processes as semiotic resources used by students and teachers in a multimodal way. A theoretical model aimed at describing gestures in mathematics activity will be outlined. To do that, we enlarge both the studies on gestures made in psychology, which generally focus on the speech-gesture relationships (McNeill 1992), as well as the semiotic studies on mathematics learning, which generally focus on the written semiotic systems and possibly on spoken utterances (for example, see the papers in Sáenz-Ludlow \& Presmeg 2006).

The paper is divided into this introduction, three main sections, and a final discussion. In the first section, we shall sketchily describe the multimodal paradigm. In the second, we shall introduce the semiotic bundle, a notion elaborated by Arzarello (2006) which enlarges the classical notion of semiotic register (Duval 2006) and allows us to study gestures within the multimodal approach. This approach is exemplified in the third section where short excerpts from two classroom episodes are discussed using two complementary analysis tools: the synchronic and the diachronic analysis. The final discussion points out the main findings of our research.

\section{Gestures and multimodality}

Over the last years, the paradigm of multimodality has developed in many fields, from neuroscience to communication to learning (Granström, House \& Kralsson 2002). The new perspective in neuroscience argues that the sensory-motor system of the brain is multimodal rather than modular (Gallese \& Lakoff 2005) in the sense that

an action like grasping...(1) is neurally enacted using neural substrates used for both action and perception, and (2) the modalities of action and perception are integrated at the level of the sensory-motor system itself and not via higher association areas. (p. 459)

Accordingly, language is inherently multimodal in this sense, that is, it uses many modalities linked together-sight, hearing, touch, motor actions, and so on. Language exploits the pre-existing multimodal character of the sensory-motor system. (ibid., p. 456)

Having its bases on these recent results in neuroscience, our research makes use of the multimodal approach for analyzing mathematics teaching-learning processes. Within this frame, we consider the role of gestures important not only as they relate to words but also to all other modalities (action on the technology, written signs, and so forth). The multimodal paradigm and specifically the analysis of gestures (for example how speech, gestures, and inscriptions are related to each other) implies the necessity of using an extremely finegrained analysis, namely scales of time of few tenths of second; hence, it requires suitable tools for collecting data, typically videotaping the activity in the classroom. The semiotic 
bundle, described in the next section, is the theoretical model that allows a semiotic fine grained analysis of the collected data according to the multimodal approach.

\section{Gestures as semiotic resources: the semiotic bundle}

As sign or semiotic resource, we consider anything that "stands to somebody for something in some respect or capacity" (Peirce 1931/1958, vol. 2, paragraph 228). Within this wide conception of sign, we regard gestures ${ }^{1}$ as important semiotic resources in strict relationship with the more traditional signs (such as spoken or written language, mathematics symbols, and so on). Recently also, Radford (2003) underlined many common features among gestures and other signs: see his notion of semiotic means of objectification. In contrast, the classical semiotic approaches that are pointed out in mathematics education place strong constraints upon the structure of the semiotic resources they consider. For instance, Ernest gives the following definition of semiotic system:

The term semiotic system is here used to comprise three necessary components. First, there is a set of signs, each of which might possibly be uttered, spoken, written, drawn, or encoded electronically. Second, there is a set of rules of sign production, for producing or uttering both atomic (single) and molecular (compound) signs....Third, there is a set of relationships between the signs and their meanings embodied in an underlying meaning structure. (Ernest 2006, p. 69)

Even more restricted is the definition given by Duval for the registers of semiotic representations:

...les systèmes sèmiotiques doivent, en effet, permettre d'accomplir les trois activités cognitives inhérentes à toute représentation: Tout d'abord, constituer une trace ou un assemblage de traces perceptibles qui soient identifiables comme une représentation de quelque chose dans un systéme déterminé. Ensuite, transformer les représentations pouvant constituer un apport de connaissance par rapport aux représentations initiales. Enfin, convertir les représentations produites dans un systéme en représentations d'un autre système, de telle façon que ces dernières permettent d'expliciter d'autres significations relatives à ce qui est représenté. Tous le systèmes sémiotiques ne permettent pas ces trois activités cognitives fondamentales, par example le morse ou le code de la route. Mais la langage naturel, les langues symboliques, les graphes, les figures géométriques, etc. les permettent. Nous parlerons alors de registres de représentation sémiotique. (Duval 1995, p. 21; emphasis in the original) ${ }^{2}$

\footnotetext{
${ }^{1}$ For a definition of gesture, see McNeill 1992, p. 11, and the comments in Edwards, this volume.

2 "The semiotic systems must effectively allow to accomplish the three cognitive activities, which concern every representation. First they must constitute a trace or a set of perceivable traces that are identifiable as $a$ representation of something in a precise system. Second, it must be possible to transform such representations only because of the rules of the system, so that fresh representations can be obtained that can constitute a contribution to knowledge with respect to the initial representations. Last, it must be possible to convert the representations produced within a system into another system, so that the latter representations permit to make explicit further meanings with respect to what is represented by them. Not all semiotic systems allow such three basic cognitive activities, for example the morse or the route code. But the natural language, the symbolic languages, graphs, geometric figures, etc. do that. We shall then speak of registers of semiotic representation" (translation by the authors).
} 
Gestures, glances, drawings, and extra-linguistic modes of expression do not satisfy all the requirements of such definitions, but they appear as basic components of the semiotic activities $^{3}$ that one sees in the classroom.

To frame all these phenomena within a semiotic perspective, it is necessary to broaden the range of signs that are considered relevant in the teaching-learning process. Over the last decade, several researchers have done this (Arzarello \& Edwards 2005; Radford 2006; Arzarello 2006; Robutti 2006; Roth 2001). Within this stream, we use an enlarged notion of semiotic system, the semiotic bundle (Arzarello 2006).

The semiotic bundle encompasses the classical semiotic registers as particular cases. Hence, it does not contradict the semiotic analysis developed using such tools but permits us to frame a wider range of semiotic activities that happen in the classroom and that could not have been properly considered within the semiotic systems and registers quoted above. A semiotic bundle is a system of signs - with Peirce's comprehensive notion of sign - that is produced by one or more interacting subjects and that evolves in time. Typically, a semiotic bundle is made of the signs that are produced by a student or by a group of students while solving a problem and/or discussing a mathematical question. Possibly, the teacher too participates in this production, and so the semiotic bundle may include also the signs produced by the teacher.

A semiotic bundle is a dynamic structure (the signs and their relationships) which can change in time because of the semiotic activities of the subjects. Its relationships can be of different types. ${ }^{4}$ A first type concerns those signs produced at the same time, such as when the subject gesticulates and speaks simultaneously. Other relationships concern signs produced at different (near or far) times, for example signs that are transformed into other signs. Two different examples are: the conversions between representations in different registers according to Duval's terminology (see note 2); the genetic conversion of a gesture into a written sign (see Arzarello 2006 and below).

The novelty of the semiotic bundle with respect to other semiotic frames present in literature is that it allows us to describe the multimodal semiotic activity of subjects in a holistic way as a dynamic production and transformation of various signs and of their relationships. In particular, it properly frames the role of gestures in mathematical activities. To get this, we consider a semiotic bundle made of speech, gestures, and inscriptions (and their relationships) built up by students and teacher and we analyze how it evolves in time. We will illustrate this through some examples that properly represent typical didactical situations we have repeatedly seen in the classrooms (from primary to upper secondary grades).

The semiotic bundle dynamics can be analyzed in two different and complementary ways. The first one is synchronic analysis, which considers the relationships among different semiotic resources simultaneously activated by the subjects at a certain moment. The second is diachronic analysis, which focuses on the evolution of signs activated by the subjects in successive moments (in short or long periods of time). Together, synchronic and

\footnotetext{
${ }^{3}$ For example, according to the definition of Duval (see the quotation above), there are three forms of semiotic activities: (a) production ("formation" in French) of representations within a semiotic register; (b) transformation of semiotic representations within the same register; (c) conversion of a semiotic representation from a register to another.

${ }^{4}$ Because of the introduction of the semiotic bundle, which enlarges the definition of semiotic register, the notion of semiotic activity given in the previous note is broadened too, provided that the three clauses listed by Duval make sense also for semiotic bundles. This is the case, as it is proved in Arzarello (2006). Hence, from now on, when we speak of semiotic activities we refer to productions, transformations and conversions of representations in semiotic bundles.
} 
diachronic analysis allow us to foreground the roles that the different types of signs (gestures, speech, inscriptions) play in students' cognitive processes. Considering semiotic bundles, we can fully grasp the evolution of learning processes and the role of gestures therein.

\section{Examples of a semiotic analysis of gestures}

The analyzed data concerning an 11th-grade classroom of a scientific course with five classes of mathematics per week, including the use of computers with mathematical software. The students have been introduced to the fundamental intuitive concepts of calculus since the beginning of the secondary school (ninth grade), with the use of different types of software (spanning the range from collecting data through sensors to dynamic geometry software and computer algebra system software) and different kinds of representations for functions (numerical tables, Cartesian graphs, and symbolic formulas). They know what the slope of a graph is, but not yet the formal notion of derivative. They also do not know the formal notion of indefinite integral as the class of anti-derivatives of a function. Moreover, they are familiar with problem-solving activities, carried out individually or in small groups, and with classroom discussions.

\subsection{Example 1}

The first example comes from an activity solved in group work. Given the graph of a function (see Fig. 1a), the task consists in sketching the graph of the slope of the given function and the graph of the function whose slope is the given function. In calculus, they are of course its derivative and primitive, but here, the students know these concepts only from a numerical and graphical but not symbolic point of view. The approach is empirical and based on activities where they are asked to explore different kinds of functions and to construct meanings. From here on, in example 1, we use the term derivative and primitive intending not their formal definition, based on limits, but this one. This approach is the base to introduce later (example 2) the formal definitions of calculus and the usual calculations of derivative and primitive.
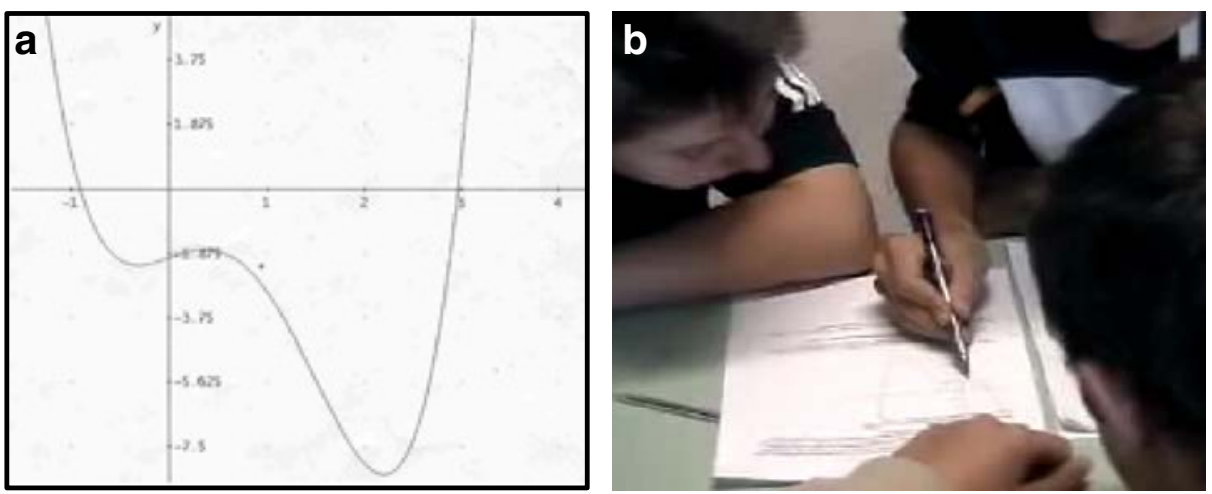

Fig. 1 a, b Graph of function activity solved in group work 


\subsubsection{Synchronic analysis}

The analysis highlights students' semiotic activities in a bundle made of words, gestures, and inscriptions. In particular, we find the following signs in the bundle:

(a) drawing a "small segment" tangent to the graph of the function and sketched by the students at different points of the graph (for example, in Fig. 2c, it is in correspondence with a local minimum of the graph);

(b) moving hand or fingers (for example index and thumb opposite each other to mimic the segment or the index to indicate the tangency point as in Fig. 3b) to mimic the tangent segment and moving it along the graph (Fig. 2a,b)

We have called such semiotic activities surfing activities and their products surfing signs: they consist of a close combination of gestures and inscriptions co-timed with (students' and teacher's) utterances. Surfing activities and signs possibly allow the students to visualize the slope of the tangent to the graph and have, therefore, a mediating function with respect to the task of drawing the derivative function.

In the following excerpt (see video "Example 1"), we see the semiotic activities of students as a holistic process where all the components of the bundle (gestures, inscriptions, utterances) are simultaneously active, intertwined with each other, and shared by the group: it is only for analysis' sake that we distinguish them.

1. S: From this point (Fig. 2a)...the slope (Fig. 2b)

2. G: It decreases and decreases less and less

3. S:...until it arrives at...

4. G: zero

5. S: zero...at this point here (He is tracing the horizontal line shown in Fig. 2c)

6. G: yes.

The gestures shown in the figures are co-timed with the italicized words in the transcription.

In line 1, when S says "from this point", he is working on the sheet where he is tracing the derivative graph with his pencil (Fig. 2a). When he says "the slope", he switches to the sheet containing the task (Fig. 2b) and traces a small horizontal segment on the graph of the function $f$ (Fig. 2c). At the same time, $\mathrm{G}$ follows with his index finger along the graph of the given function (Fig. 2a,b). It is interesting to observe that G's utterances (no. 2) and cotimed gestures both refer to the graph of the given function. In contrast, S's utterances refer to the derivative function, while his gestures with the pencil (Fig. 1b) switch to the given function. The students are in tune with each other: see the dialogue in which one student is
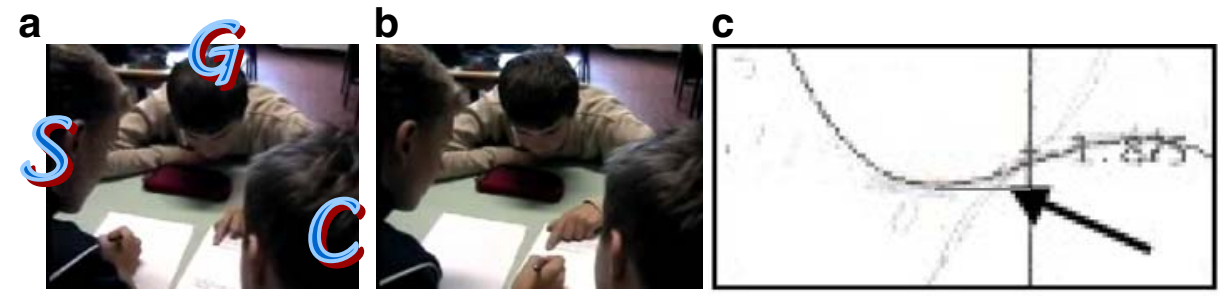

Fig. 2 a-c Mimicking the tangent segment and moving it along the graph 

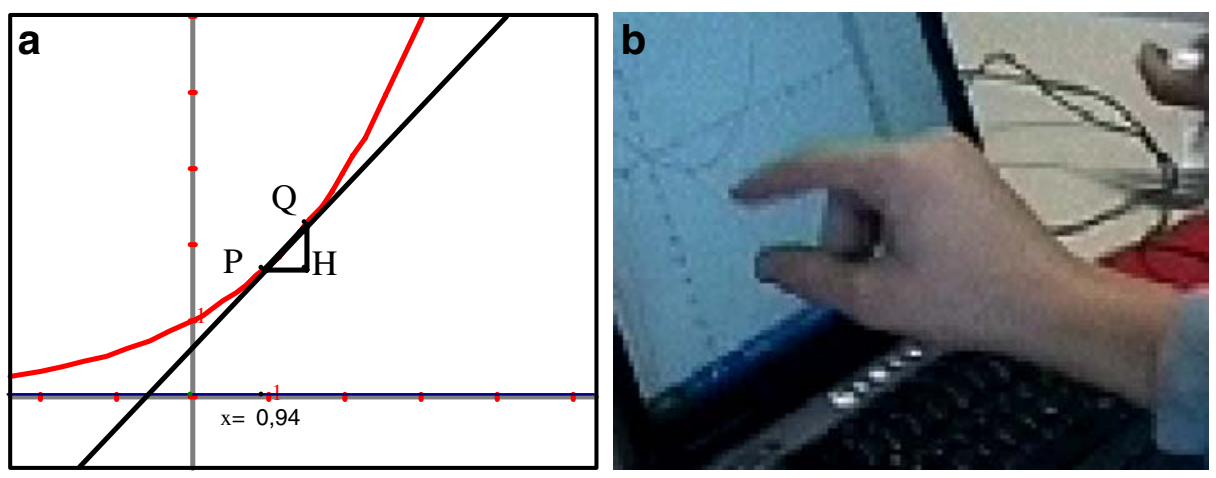

Fig. 3 a, b From the screen to the gesture

able to anticipate or complete the other's statements, namely, they are sharing the semiotic bundle where all these components are active and interacting.

The surfing activities of students support their embodied approach to the slope of a graph both in its local and global features.

\subsubsection{Diachronic analysis}

While the synchronic analysis permits us to interpret the role of the surfing signs in students' ongoing activity, through a diachronic analysis, we can gain insight both on its genesis and on the role of such a sign with respect to other signs, eventually written signs, for example the graph that is required as a solution of the task.

The genesis of the surfing sign can be traced back to the use of artifacts during previous activities. In particular, in the year before, the students had intensively explored the geometric configuration representing the incremental ratio within the Cabri environment (Fig. 3a): they had acquired the habit of dragging the point $P$ along the graph of a function and of changing the value of the increment $\mathrm{PH}$ to study the ratio $\mathrm{QH} / \mathrm{PH}$ while $P$ moves.

They had also used the "zoom function" of the symbolic-graphic calculator which allows the user to iteratively magnify the graph of a (differentiable) function around a point until it looks like a segment line. The videos of such activities show how they sometimes use their fingers (thumb and index opposite each other, see Fig. 3b) for surfing through the graph directly on the screen of the computer without dragging the quasi-tangent PQ of Fig. 3a with the mouse. Possibly, the roots of the surfing sign in the activities of the excerpt are in these past practices: in fact, in another part of the session, whose protocols are not reported here, the students explicitly recall their previous practices.

Having its roots in previous activities and being shared in the group, surfing signs play an important role in the solution of the task. We can observe their traces by looking at how students have drawn the graph of the slope function. Before drawing the final graph (Fig. 4b), they produce what they call an "approximate graph", which serves as a scaffolding structure (Fig. 4a).

Diachronic analysis shows long- and short-term conversions of signs: from dragging and surfing in the Cabri environment to the surfing signs in paper and pencil environments 1 year later; from surfing with fingers to surfing with pencil to the production of the segments of Fig. $4 \mathrm{a}$ to the final graph of Fig. $4 \mathrm{~b}$. All these signs are co-timed with a variety of utterances as in the excerpt above. 
a

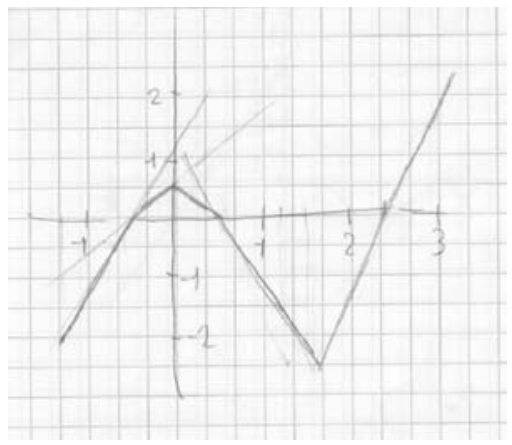

b

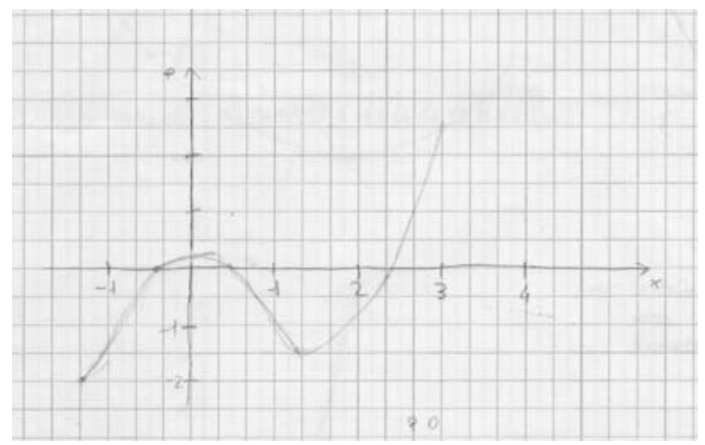

Fig. 4 a, b Drawing the final graph

The diachronic analysis shows how a semiotic bundle shared by a group of students can be made of components that come from previous practices: they come from the "memory of the class" (Brousseau \& Centeno 1991) and are suitably transformed and converted within the fresh semiotic bundle.

\subsection{Example 2}

The second example is taken from a discussion that occurred in the same classroom some time later. In a previous task, the students had been asked to find the equation of the derivative of the function $f(x)=x^{4}-3 x^{3}+4$ (the students were given also its graph, see Fig. 5a) starting from its definition (namely from the incremental ratio). Even though the students had previously been introduced to the formula of the incremental ratio and its geometrical meaning, most of them failed in the proposed task. The teacher therefore decided to deepen the issue through a class discussion, focused on finding the formula of the tangent line to the given graph at the point $P(1,2)$. He set up the scene, drawing the graph of the function on the blackboard and writing its equation. Then he asked A, a brilliant student who was a member of the only group that had completed the task, to describe the procedures and reasoning that his group had used (lines 7-11 refer to video "Example 2a", lines 12-14 to video "Example 2b").

7. A: Well: basically we had to determine the..., the slope of the function at a point called $x$ (Fig. 5a: A is marking " $x$ "), we do like that (he is tracing a vertical segment reaching the point on the graph corresponding to $x$ ); then, we compute a little interval $x+h$, (writing $x+h$ and tracing a corresponding vertical segment) and at this point we
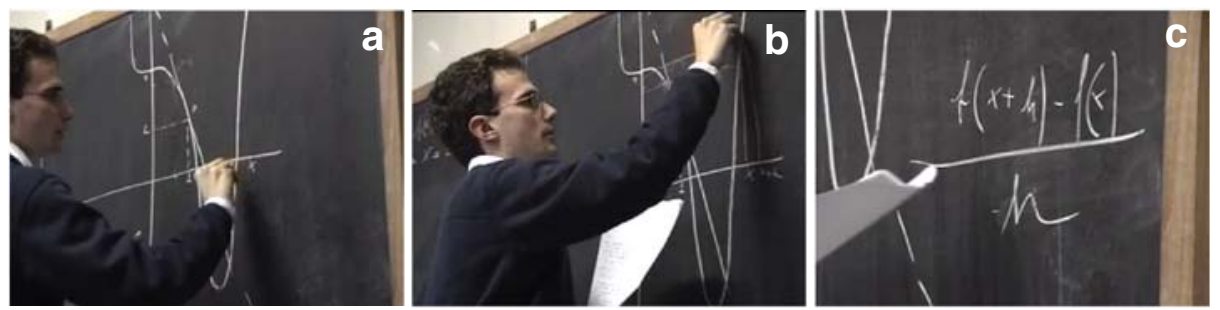

Fig. 5 a-c Finding the equation of the derivative of the function 
execute the classic operation $\Delta x$, uhm..., we find out also the $y$, of course: the $y$ are... this is $f(x)$ (Fig. 5b), this is a generic function (then he writes the formula of the incremental ratio, shown in Fig. 5c).

The teacher at this point intervenes and directs the students' attention to the meaning of the incremental ratio (L and $\mathrm{G}$ are two other students):

8. T: So, this you've written, $f(x+h)$ minus $f(x)$ divided by $h$, what does it represent?

9. A: Practically it represents the slope at this point here [he is pointing at the point $(x$, $f(x)$ ) in the graph]. Because $h$ is a wonderful invention (Fig. 6a: A is pointing to $h$ ) that, practically, is a...it is a...it is an infinitesimal; not, not a true number, since it is something that is not zero, but at the end, we can exclude it, treating it almost as if it were zero, but it is not zero, otherwise, otherwise we would nullify (pointing at the numerator of the incremental ratio in Fig. 6a).

10. L: (overlapping): It is so small (Fig. 6b,c: two pointed fingers, approaching each other), that it tends to zero (Fig. 6d: right hand moving horizontally, from left rightwards)

11. T: Eh! So, the smaller it is $h$ (Fig. 7a,b: two pointed fingers) [...]

12. G: That is the more it is smaller, the more it is precise.

13. T: (overlapping): the more we have information (Fig. 7c: thumb and forefinger touching) on the slope

14. A: with numbers we could go always smaller, smaller, smaller....We could choose the intervals (Fig. 7d) always more, more...reduced, but we will never arrive to the precision level that is $h$.

By asking about the formula of the incremental ratio, the teacher is stimulating the students towards a conversion of the symbolic algebraic formula in terms of the graphicgeometric and numeric frames (no. 8). To explain the link between these two frames, A focuses on the nature of " $h$ ", pointing out its particular status; $h$ is referred to as a special number, actually something that is not truly a number, but a "wonderful invention": the special character of $h$ is pinpointed by the term "infinitesimal", explicitly described as a number that is different from zero, but which can be treated "almost as zero".

Such a construction presents clearly intrinsic contradictions whose discussion is beyond the scope of the present paper. ${ }^{5}$ At this point, L contributes to A's account (no. 10) and focuses attention on a crucial element: the fact that $h$ is to be considered not only small, but getting smaller and smaller. This dynamic process is expressed not only in speech but also in the co-occurring gesture of the thumb and index finger approaching each other (Fig. 6b,c). We find such a sign quite widespread in the classroom. Usually, it appears co-timed with utterances referring to increments of the $x$ or the $y$ variables and has accordingly been called delta gesture. In the example, it refers to $h$; the iconic features of the gesture with respect to a segment in the Cartesian plane become blended in the semiotic bundle with the symbolic reference to the limit process (for the concept of blending, see Edwards, this volume): see in Fig. $6 \mathrm{~d}$ how the gesture evolves in depicting the arrow of the limit symbol. The long-time

\footnotetext{
${ }^{5}$ The elimination of actual infinitesimals from Analysis made by Weierstrass has not definitely settled this delicate point: see Robinson's non-standard Analysis or the most recent so called microanalysis (Bell 1998). Also from a cognitive point of view things are not settled at all: see Tall and Tirosh (2001).
} 

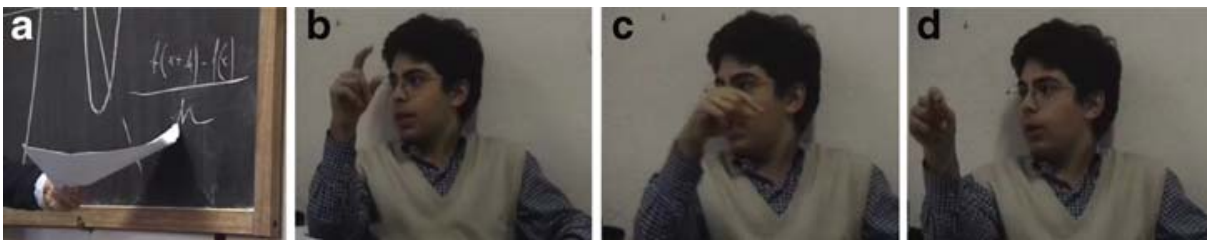

Fig. 6 a-d Different gestures referring to the limit

diachronic analysis shows that this gesture is rooted in the previous year students' activities with the (first and second) finite differences of functions.

The same semiotic bundle is then shared by the teacher (no. 11). The teacher is in fact showing a delta gesture (see Fig. 7b); at the same time, he is reformulating what $\mathrm{L}$ and A have just proposed and is adding new elements: he is correlating the decreasing of $h$ to the increasing of precision for the computation of the slope. By coordinating with the students' words and gestures, the teacher is fostering the connections among the mathematical elements that are crucial with respect to the evolution of knowledge: (1) the decreasing of $h$, (2) the approaching of the points corresponding to the incremental ratio on the graph, and (3) the precision of the approximated slope value. In A's subsequent intervention, the same elements become correlated to the inscriptions at the blackboard (no. 14, Fig. 7d). The teacher's action develops in the bundle in a way that we find many other times in our protocols: he coordinates with the semiotic resources used by the students and then guides the development of knowledge using these resources. Typically, the teacher uses the same gestures as the students and rephrases their sentences using precise mathematical language. Doing so, he supports the students towards a correct scientific meaning. We have called such a mechanism semiotic game: for a wider discussion, see the work of Arzarello and Paola (2007) and Arzarello and Robutti (2008). In our research, we have discovered the semiotic game through our model. It was unconsciously used by a teacher of our research group. After the discovery, it has become part of a conscious methodology now used by all the teachers in our group.

\section{Discussion}

Elaborating from the given episodes and analysis, we can draw some consequences on the role of gestures in mathematics teaching-learning. We shall pinpoint them from three different points of view.

1. Epistemic nature of the semiotic bundle. The semiotic bundle model permits us to consider the multimodal activities of the students. The synchronic and diachronic analyses show the complex intertwining among gestures, speech, and inscriptions in
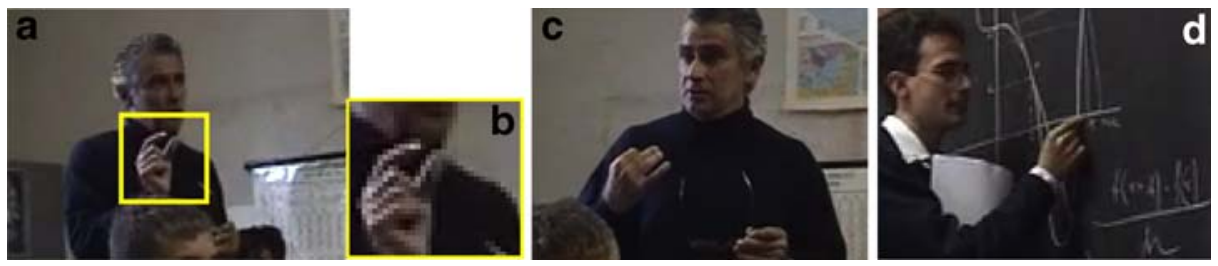

Fig. 7 a-d Coordination between gestures: the semiotic game of the teacher 
learning mathematics. These ingredients jointly support the thinking processes of students in a unitary way. For example, consider the role of the surfing signs in example 1: it is the semiotic bundle as a whole to assume an epistemic value, namely to support students in their cognitive progress towards new knowledge (the notion of slope function and the way it depends on its "primitive"). On the other side, the single ingredients of the bundle per se show more pragmatic aspects, namely they are more goal-directed (for example the careful surfing with the pencil by $\mathrm{S}$ and with the finger by G: Fig. 2a,b). Similar observations concern also the example 2: here, it is the dialectic among the different ingredients of the semiotic bundle active in the classroom to foster students' knowledge. In a sense, it is the multimodality of the semiotic bundle to guarantee the improvement of students' cognition more than this or that single component of the semiotic bundle.

2. Gestures as personal signs. Signs may be of two different categories: institutional (mathematical) or personal. A sign is institutional if established by an institution (for example the school); it is personal if it is an idiosyncratic production of the subject (see Bartolini Bussi \& Mariotti 2008 for a modern discussion of this Vygotskian point). For example, the incremental ratio $[f(x+h)-f(x)] / h$ is an institutional sign, while the surfing signs of example 1 are personal signs. Sometimes, the personal signs are able to support themselves the transition to the institutional ones and to the sharing of common treatment rules. For example, the surfing signs reveal themselves to be a useful tool for managing the notion of local and global slope of a function and for producing the graph of its derivative. Other times, this does not happen and the mediation of the teacher becomes necessary, for example through a semiotic game (example 2).

In these processes, gestures can play an important double role. First, as components of the semiotic bundle, they can support thinking processes of students and promote the transition personal-institutional with suitable conversions from one sign to another. In example 1, the surfing practices are converted to different signs that help students to grasp the notion of slope of a graph. In example 2, it is the semiotic game of the teacher that supports students towards the more formal scientific notion of derivative. Second, gestures have also a communicative function. This is true both concerning the teacher and the students. The teacher may use them as communicative tools in a conscious way. But gesture may play this role also for the students, even if in a less conscious way. In fact, they allow alternative ways of embodying and organizing information that the student is not able to express in purely verbal or formal ways. For example, consider the contribution of the surfing signs in example 1 and the role of L's gestures in "explaining" A's arguments in example 2. Moreover, students are reactive to the teacher's gestures during the semiotic game. Of course this is the result of a teaching style shared in the classroom where using gestures is not prohibited but even encouraged by the teacher.

3. The semiotic game of the teacher. Semiotic games constitute an important strategy in the process of appropriation of the culturally shared meaning of signs. They allow the teacher to become suitably in tune with students' languages and, conversely, they allow students to achieve resonance with the teacher's languages and, through them, with the institutional knowledge. In order that such opportunities can be concretely realized, the teacher must be aware of the role that multimodality and semiotic games can play in teaching. Awareness is necessary for designing the conditions that foster positive learning experiences and for adapting her/his intervention techniques to the specific didactic activity. Diachronic and synchronic analysis can help her/him in this task. For example, she/he can monitor the evolution of students' productions during one or more 
learning episodes (diachronic analysis at an intermediate timescale: from a few hours to some days) in order to realize whether their signs and practices in the semiotic bundle are developing towards the institutional ones. Furthermore, synchronic analysis can allow the teacher to accomplish her/his semiotic mediation using the different components active in the semiotic bundle. Considering larger scales (months or years), diachronic analysis can allow the teacher to understand the evolution of the semiotic resources and practices in the classroom within different semiotic bundles.

In our example, diachronic analysis has helped the teacher (and the researchers) to analyze students' actions, productions, and communications while facing the multifaceted notion of derivative. The "small segment" with the "surfing" practices has been powerful in helping students to grasp the local slope of a function and in the production of the derivative graph (example 1). However, such a sign was not enough to support students in grasping the formal aspects of the incremental ratio. Hence, the teacher designed a suitable environment for supporting the discussion where a more complex semiotic bundle was built and shared in the classroom (example 2). This semiotic bundle contained institutional and personal signs (some of which came from the memory of the class), the different inscriptions on the blackboard (graphical and symbolic), as well as the students' and teacher's words and gestures (see Figs. 5a-c, 6a-d, and 7a-d). It is by exploiting the richness of such a bundle that the teacher has been able to perform his semiotic game.

To summarise, in a nutshell, the sense of our findings, we could say that they broaden McNeill's claim that "gesture and the spoken utterance [are] different sides of a single underlying mental process" (McNeill 1992, p. 1), namely that "gesture and language are one system" (ibid., p. 2). In fact, the unitary nature of processes within the semiotic bundle shows that under mental processes, there is a richer and more complex system.

\section{References}

Arzarello, F. (2006). Semiosis as a multimodal process, Revista latino americana de investigación en matemática educativa, vol. Especial, pp. 267-299.

Arzarello, F., \& Edwards, L. (2005). Gesture and the construction of mathematical meaning (research forum 2). In H. L. Chick, \& J. L. Vincent (Eds.), Proceedings of the 29th Conference of the International Group for the Psychology of Mathematics Education (vol. 1 (pp. 122-145). Melbourne, Australia: University of Melbourne.

Arzarello, F., \& Paola, D. (2007). Semiotic games: the role of the teacher. In J. Woo, H. Lew, K. Park, \& D. Seo (Eds.), Proceedings of the 31st Conference of the International Group for the Psychology of Mathematics Education (vol. 2 (pp. 17-24). Seoul, Korea: The Korea Society of Educational Studies in Mathematics.

Arzarello, F., \& Robutti, O. (2008). Framing the embodied mind approach within a multimodal paradigm. In L. English, M. Bartolini Bussi, G. Jones, R. Lesh, \& D. Tirosh (Eds.), Handbook of international research in mathematics education (pp. 720-749, 2nd ed.). Mahwah, NJ: Erlbaum.

Bartolini Bussi, M. G., \& Mariotti, M. A. (2008). Semiotic mediation in the mathematics classroom: artefacts and signs after a Vygotskian perspective. In L. English, M. Bartolini Bussi, G. Jones, R. Lesh, \& D. Tirosh (Eds.), Handbook of international research in mathematics education (pp. 720-749, 2nd ed.). Mahwah, NJ: Erlbaum.

Bell, J. L. (1998). A primer of infinitesimal analysis. Cambridge: Cambridge University Press.

Brousseau, G., \& Centeno, J. (1991). Rôle de la mémoire didactique de l'enseignant [The role of the teacher's didactic memory]. Recherches en Didactique des Mathématiques, 11(2-3), 167-210.

Duval, R. (1995). Sémiosis et pensée humaine. Bern: Peter Lang.

Duval, R. (2006). A cognitive analysis of problems of comprehension in a learning of mathematics. Educational Studies in Mathematics, 61, 103-131. doi:10.1007/s10649-006-0400-z. 
Ernest, P. (2006). A semiotic perspective of mathematical activity: The case of number. Educational Studies in Mathematics, 61, 67-101. doi:10.1007/s10649-006-6423-7.

Gallese, V., \& Lakoff, G. (2005). The brain's concepts: The role of the sensory-motor system in conceptual knowledge. Cognitive Neuropsychology, 21, 1-25.

Granström, B., House, D., \& Kralsson, I. (Eds.) (2002). Multimodality in language and speech systems. Berlin: Springer.

McNeill, D. (1992). Hand and mind: What gestures reveal about thought. Chicago, IL: Chicago University Press.

Peirce, C. S. (1931/1958). In C. Hartshorne, P. Weiss, \& A. Burks (Eds.), Collected papers (vol. I-VIII). Cambridge, MA: Harvard University Press.

Radford, L. (2003). Gestures, speech, and the sprouting of signs: A semiotic-cultural approach to students' types of generalization. Mathematical Thinking and Learning, 5(1), 37-70. doi:10.1207/ S15327833MTL0501_02.

Radford, L. (2006). The anthropology of meaning. Educational Studies in Mathematics, 61, 39-65. doi:10.1007/s10649-006-7136-7.

Robutti, O. (2006). Motion, technology, gesture in interpreting graphs. International journal for technology in mathematics education, 13(3), 117-126.

Roth, W. M. (2001). Gestures: Their role in teaching and learning. Review of Educational Research, 71(3), 365-392. doi:10.3102/00346543071003365.

Sáenz-Ludlow, A., \& Presmeg, N. (Eds.). (2006). Semiotic perspectives in mathematics education: A PME Special Issue. Educational Studies in Mathematics, 61, 1-2. doi:10.1007/s10649-005-9001-5.

Tall, D., \& Tirosh, D. (2001). Infinity-The never-ending struggle. Educational Studies in Mathematics, 48 (2-3), 199-238. doi:10.1023/A:1016000710038. 